\title{
Benign Paroxysmal Positional Vertigo with Simultaneous Involvement of Multiple Semicircular Canals
}

\author{
Dae Bo Shim, Chang Eun Song, Eun Jung Jung, Kyung Min Ko, \\ Jin Woo Park, and Mee Hyun Song \\ Department of Otorhinolaryngology, Myongji Hospital, Goyang, Korea
}

Received November 4, 2014

Revised November 28, 2014

Accepted December 2, 2014

Address for correspondence

Mee Hyun Song, MD, PhD

Department of Otorhinolaryngology,

Myongji Hospital,

55 Hwasu-ro 14beon-gil,

Deogyang-gu, Goyang 412-270,

Korea

Tel $+82-31-810-5406$

Fax +82-31-969-0500

E-mail meehyun924@hanmail.net
Background and Objectives: Benign paroxysmal positional vertigo (BPPV) generally involves a single semicircular canal (single canal BPPV) but it has been reported that more than one semicircular canal on either the same or the opposite side can be involved in $6.8-20 \%$ of the cases (multiple canal BPPV). In this study, the clinical characteristics of multiple canal BPPV were analyzed and compared to those of single canal BPPV. Subjects and Methods: Retrospective analysis was performed on 1054 consecutive patients diagnosed with BPPV. Multiple canal BPPV was diagnosed when the combination of typical nystagmus was provoked by the Dix-Hallpike and supine head roll tests. Canalith repositioning maneuver was performed sequentially starting with the semicircular canal causing more severe nystagmus or symptoms. Clinical characteristics and the treatment course were statistically compared between single canal BPPV and multiple canal BPPV. Results: Among the 1054 patients, single canal BPPV was diagnosed in 1005 patients (95.4\%) while multiple canal BPPV was diagnosed in 49 patients (4.6\%). BPPV involving semicircular canals on the same side was more common (79.6\%) than BPPV with bilateral involvement. The most common combination of the involved canals was ipsilateral posterior and horizontal semicircular canals (63.3\%). Multiple canal BPPV was significantly more associated with underlying otologic diseases, especially labyrinthitis. Multiple canal BPPV required more treatment sessions and longer duration of treatment to achieve resolution of nystagmus and symptoms. Conclusions: As all cases of multiple canal BPPV were treated successfully although a longer duration of treatment and more treatment sessions were required compared to single canal BPPV, the results of our study could aid in making an accurate diagnosis and providing appropriate treatment of multiple canal BPPV.

Korean J Audiol 2014;18(3):126-130

KEY WORDS: Benign paroxysmal positional vertigo $\cdot$ Multiple $\cdot$ Labyrinthitis · Semicircular canal.

\section{Introduction}

Benign paroxysmal positional vertigo (BPPV) is widely accepted as the most common cause of recurrent vertigo. ${ }^{1)}$ Vertigo is known to be triggered by the gravitational movement of otoliths in response to head movement when the otoliths within the utricular macula disengage and enter one or more of the semicircular canals. More commonly, otoliths migrate into a single semicircular canal (single canal BPPV). In rare cases,

This is an Open Access article distributed under the terms of the Creative Commons Attribution Non-Commercial License (http://creativecommons. org/licenses/by-nc/3.0/) which permits unrestricted non-commercial use, distribution, and reproduction in any medium, provided the original work is properly cited. multiple semicircular canals on the same or both sides are involved, which is termed as multiple canal BPPV. ${ }^{2,3)}$ Multiple canals have been reported to be involved in $6.8-20 \%$ of BPPV cases. $^{3-7)}$

Multiple canal BPPV can manifest with diverse combinations of nystagmus and may be confused with positional vertigo of central origin. On the other hand, findings of inaccurately executed positional tests in single canal BPPV might be mistaken for multiple canal involvement. ${ }^{8,9)}$ For these reasons, understanding the clinical features of multiple canal BPPV is very important, and hence, the authors investigated the clinical characteristics of multiple canal BPPV in comparison to single canal BPPV. 


\section{Subjects and Methods}

A retrospective review of medical records including physician's notes and patient questionnaires was performed for 1054 BPPV patients who visited our dizziness clinic between January 2010 and December 2013. The affected side and the involved semicircular canal were identified by performing positional nystagmus tests using a computerized video eye movement recorder (SLMED, Seoul, Korea). The provocation test methods and the diagnostic criteria for BPPV were in accordance with the guidelines proposed by the American Academy of Otolaryngology-Head and Neck Surgery. ${ }^{8)}$ When the test was positive for skew deviation or positive for abnormal neurologic examination, magnetic resonance imaging of the brain was performed to rule out organic lesions in the central nervous system.

Posterior canal BPPV (p-BPPV) was diagnosed when a characteristic upbeating-torsional nystagmus was identified with a latency period, showing an increment and decrement pattern of vertigo and nystagmus within a time period of 60 seconds from the onset of nystagmus. The two subtypes of horizontal canal BPPV (h-BPPV) can be further divided into geotropic type [h-BPPV (Geo)] and apogeotropic type [h-BPPV (Apo)] based on the supine head roll test. The geotropic type can be diagnosed when a typical direction-changing geotropic positional nystagmus is identified on the supine roll test. In the apogeotropic type, the direction-changing nystagmus is apogeotropic. Anterior canal BPPV (a-BPPV) was diagnosed when a typical torsional downbeating nystagmus that resolved within 60 seconds was seen with a short latency period after performing the Dix-Hallpike test on the unaffected side, or when downbeating nystagmus was identified on both sides after performing the Dix-Hallpike test. When the downbeating nystagmus was seen on both sides or the torsional nystagmus on one side was weak, the affected side was determined based on the torsional component observed in supine. Multiple canal BPPV was diagnosed when the combination of typical nystagmus was provoked by the Dix-Hallpike and supine head roll tests.

During each clinic visit, the patients received a single treatment procedure. If the provoked nystagmus was present dur- ing the following clinic visit, the procedure was repeated. The following visits were made within 1 to 7 days after the initial visit during which the vertigo symptom and positional nystagmus were evaluated. Successful treatment was defined as resolution of typical nystagmus in positional tests along with the resolution of positional vertigo. The treatment procedures for each subtype of single canal BPPV included modified Epley maneuver for $\mathrm{p}-\mathrm{BPPV}$, modified Lempert maneuver for h-BPPV (Geo), new cupulolith repositioning maneuver ${ }^{10)}$ for h-BPPV (Apo), and Yacovino maneuver ${ }^{11)}$ for a-BPPV. For multiple canal BPPV, a combination of these procedures was performed starting with the treatment for the canal causing more severe nystagmus or symptoms. ${ }^{4}$

Clinical characteristics of the total 1054 patients with typical BPPV were statistically compared between the single canal BPPV patients and multiple canal BPPV patients. With respect to the underlying or accompanying conditions, we evaluated the presence of head trauma, chronic otitis media in the affected side, labyrinthitis in the affected side, and Meniere's disease. Labyrinthitis was diagnosed by audiologic tests and vestibular function tests, i.e., simultaneous vestibular neuritis and sudden sensorineural hearing loss in the affected side. We analyzed the combination of affected semicircular canals for making the diagnosis of multiple canal BPPV. Among the 1054 patients diagnosed as having BPPV, 874 patients were included for the analysis of treatment-related measures after excluding 52 patients who were lost to follow-up and 128 patients who did not receive the typical treatment procedures previously described such as watchful waiting. Of 874 patients receiving the typical treatment procedures, there were 1005 patients with single canal BPPV (Group 1) and 49 patients with multiple canal BPPV (Group 2). Treatment-related clinical parameters for statistical analyses were the number of treatment sessions needed to achieve resolution of symptoms and nystagmus and the duration of treatment. SPSS version 18 (SPSS Inc., Chicago, IL, USA) was used to conduct the Student's t-test and Pearson $\chi^{2}$ test. Statistical comparison was considered significant when the $p$-value was less than 0.05 .

Table 1. Demographic data of multiple canal benign paroxysmal positional vertigo compared to single canal benign paroxysmal positional vertigo

\begin{tabular}{lccc}
\hline \multicolumn{1}{c}{ Group } & Single canal BPPV $(\mathrm{n}=1005)$ & Multiple canal BPPV $(\mathrm{n}=49)$ & $\mathrm{p}$-value \\
\hline Age (mean \pm SD, years) & $54.4 \pm 14.8$ & $54.3 \pm 14.7$ & $0.960^{*}$ \\
Sex ratio (male:female) & $257: 748$ & $13: 36$ & $0.881^{\dagger}$ \\
Duration of vertigo (days) & $5.4 \pm 11.9$ & $6.9 \pm 13.4$ & $0.367^{*}$ \\
Interval of clinic visit (days) & $2.1 \pm 1.4$ & $1.7 \pm 1.3$ & $0.098^{*}$ \\
Idiopathic BPPV (numbers) & $861(85.7 \%)$ & $32(65.3 \%)$ & $<0.001^{\dagger}$ \\
\hline
\end{tabular}

*Student's, t-test, ${ }^{\dagger} \chi^{2}$ test. BPPV: benign paroxysmal positional vertigo, $\mathrm{n}$ : total number of patients in each group 


\section{Results}

Among the 1054 BPPV patients, 270 were males and 784 were females, with a mean age of $54.4 \pm 14.8$ years (range, 11-89 years). The mean age was 54.4 years and 54.3 years for patients with single canal BPPV and multiple canal BPPV, respectively, which did not differ significantly. Patients' gender, the time interval between the onset of symptoms and the first clinical visit, and the interval between the clinic visits were not significantly different between the two groups (Table 1). Among the 1054 BPPV patients, 1005 patients (95.4\%) were diagnosed with single canal BPPV including 514 patients (48.8\%) with p-BPPV, 443 patients $(42.0 \%)$ with h-BPPV [h-BPPV (Geo): 183 (17.4\%), h-BPPV (Apo): 260 (24.6\%)], and 48 patients (4.6\%) with a-BPPV (Fig. 1). Forty-nine patients (4.6\%) were diagnosed with multiple canal BPPV. With respect to the combination of canals involved, 39 patients (79.6\%) demonstrated ipsilateral canal involvement with ipsilateral posterior

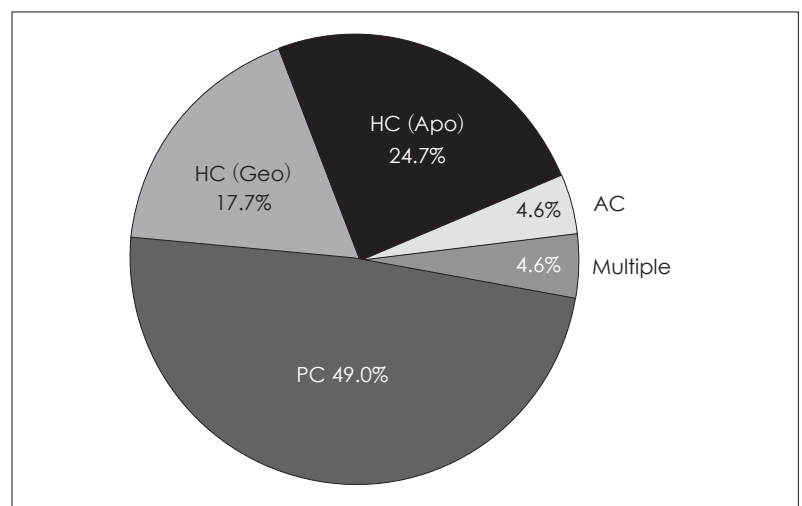

Fig. 1. The incidence of multiple canal benign paroxysmal positional vertigo and each subtype of single canal benign paroxysmal positional vertigo. The incidence of multiple canal benign paroxysmal positional vertigo is $4.6 \%$ (49 patients) in a total 1054 patients. $\mathrm{PC}$ : posterior canal benign paroxysmal positional vertigo, $\mathrm{HC}(\mathrm{Geo})$ : geotropic subtype of horizontal canal benign paroxysmal positional vertigo, HC (Apo): apogeotropic subtype of horizontal canal benign paroxysmal positional vertigo, AC: anterior canal benign paroxysmal positional vertigo, Multiple: multiple canal benign paroxysmal positional vertigo. and horizontal canals being the most frequent combination (31 cases, 63\%) (Table 2).

Cases of multiple canal BPPV were more likely to have un-

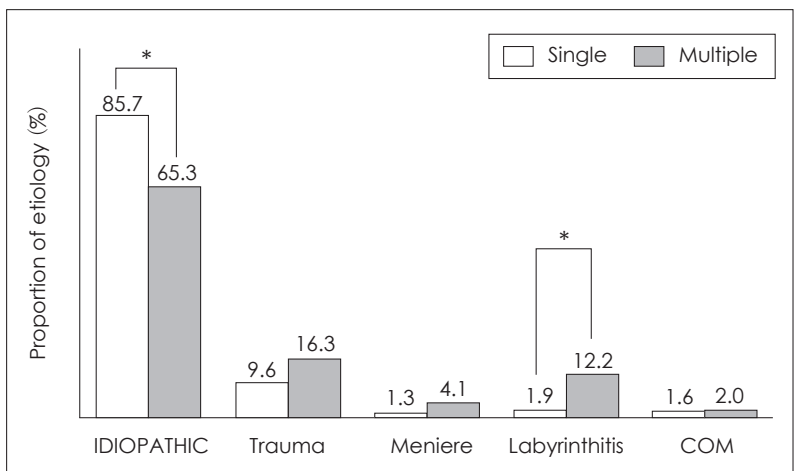

Fig. 2. Causes of multiple canal benign paroxysmal positional vertigo compared to those of single canal benign paroxysmal positional vertigo (BPPV). Multiple canal benign paroxysmal positional vertigo is more likely to be caused by underlying otologic diseases especially labyrinthitis when compared to single canal benign paroxysmal positional vertigo. ${ }^{*} p<0.05, \chi^{2}$ test. IDIOPATHIC: idiopathic BPPV, COM: chronic otitis media, Single: single canal benign paroxysmal positional vertigo, Multiple: multiple canal benign paroxysmal positional vertigo.

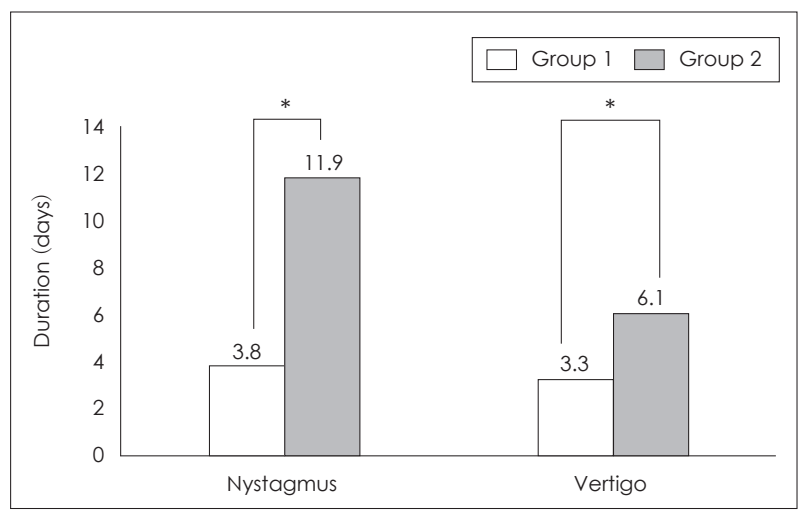

Fig. 3. Duration of for the disappearance nystagmus and vertigo in multiple canal benign paroxysmal positional vertigo compared to that in single canal benign paroxysmal positional vertigo. Multiple canal benign paroxysmal positional vertigo (Group 2) needs a longer time duration for the disappearance of vertigo symptom and nystagmus than single canal benign paroxysmal positional vertigo (Group 1). ${ }^{*} p<0.05$, Student's t-test.

Table 2. Prevalence and involved canals of multiple canal benign paroxysmal positional vertigo compared with those in the previous reports

\begin{tabular}{|c|c|c|c|c|c|c|c|c|c|c|}
\hline \multirow[b]{2}{*}{ Study (author, year) } & \multicolumn{2}{|c|}{ Number of patients } & \multicolumn{8}{|c|}{ Involved canals ( $n, \%)$} \\
\hline & Total & $\begin{array}{c}\text { Multiple } \\
\text { canal }(n, \%)\end{array}$ & Both PCs & $\begin{array}{l}\text { Both } \\
\text { ACs }\end{array}$ & $\mathrm{PC}+\mathrm{iHC}$ & $\mathrm{PC}+\mathrm{CHC}$ & $P C+i A C$ & $\mathrm{PC}+\mathrm{CAC}$ & $\mathrm{AC}+\mathrm{iHC}$ & $\mathrm{AC}+\mathrm{CHC}$ \\
\hline Lopez-Escamez, et al.," 2005 & 70 & $14(20)$ & $5(35.7)$ & $?$ & $9(64.3)$ & - & - & - & - & - \\
\hline Pollak, et al.., 2006 & 232 & $16(6.8)$ & $16(100)$ & - & - & - & - & - & - & - \\
\hline Tomaz, et al.., 2009 & 2345 & $287(12.2)$ & $233(82.2)$ & $19(6.6)$ & $23(8.0)$ & $9(31.4)$ & - & $2(0.7)$ & - & $1(0.3)$ \\
\hline Balatsouras, ${ }^{3)} 2012$ & 345 & $32(9.3)$ & $21(65.6)$ & - & $5(15.6)$ & $2(6.3)$ & - & - & $2(6.3)$ & $2(6.3)$ \\
\hline Soto-Varela, et al., ${ }^{4)} 2013$ & 836 & $46(8.0)$ & $34(73.9)$ & - & $1(2.2)$ & $2(4.3)$ & $9(19.6)$ & - & - & - \\
\hline This study & 1054 & $49(4.6)$ & $5(10.2)$ & - & $31(63.3)$ & $5(10.2)$ & $2(4.1)$ & - & $6(12.2)$ & - \\
\hline
\end{tabular}

PC: posterior semicircular canal, AC: anterior semicircular canal, $\mathrm{HC}$ : horizontal semicircular canal, i: ipsilateral, c: contralateral, ?: not described, n: total number of patients in each study 
derlying conditions such as head trauma, Meniere's disease, labyrinthitis, or otitis media. Incidence of labyrinthitis, in particular, was significantly greater in patients with multiple canal BPPV compared to patients with single canal BPPV $(p<0.05)$ (Fig. 2).

When the treatment duration to achieve resolution of nystagmus was compared between patients with single canal BPPV (Group 1) and patients with multiple canal BPPV (Group 2), Group 1 demonstrated a significantly shorter treatment duration compared to Group 2 ( $3.8 \pm 4.3$ days vs. $11.9 \pm 12.6$ days). Duration of vertigo symptom was also significantly longer in Group 2 (6.1 \pm 9.3 days) than in Group 1 (3.3 \pm 7.1 days) $(p<$ $0.05)$ (Fig. 3). Likewise, Group 2 received more treatment procedures $(3.2 \pm 2.9)$ than Group $1(1.5 \pm 1.1)(p<0.05)$.

\section{Discussion}

Previous studies reported that the prevalence of multiple canal involvement was $6.8-20 \%$ of the total BPPV cases, whereas our study showed that it was $4.6 \%$, which was significantly lesser than the published data (Table 2). ${ }^{3-7)}$

With respect to demographics, previous studies reported that patients with multiple canal BPPV were older compared to patients with single canal BPPV. ${ }^{4)}$ In contrast, our results did not show a significant difference between patients with single and multiple canal BPPV in terms of age or sex.

Many studies reported that both the posterior semicircular canals are most commonly affected in multiple canal BPPV., ${ }^{3,5,6)}$ However, our study showed that ipsilateral posterior and horizontal canals is the most common combination, which is in accordance with the study by Lopez-Escamez, et al. ${ }^{7)}$ The incidence of bilateral posterior canal BPPV may have been overestimated in other reports considering the possible inclusion of cases with pseudobilateral posterior canal BPPV; this concept has been described by Steddin and Brandt. ${ }^{9)}$ Pseudobilateral posterior canal BPPV includes misdiagnosed cases with single canal BPPV involving the posterior semicircular canal, where inappropriate head positioning during the DixHallpike test of the unaffected ear causes displacement of the otoliths toward the cupula evoking an inhibitory nystagmus in the affected canal. ${ }^{3)}$ Pseudobilateral posterior canal BPPV should be suspected when there is asymmetric nystagmus and symptoms of different intensity during right and left Dix-Hallpike tests, or when the torsional component of nystagmus is seen in supine straight-head hanging position. ${ }^{3)}$ Other difficulties that may hinder the correct diagnosis of multiple canal BPPV are cases of BPPV involving bilateral anterior or bilateral horizontal semicircular canals. ${ }^{3)}$ Since the torsional component of nystagmus is weak compared to the downbeating component in cases of anterior semicircular canal BPPV and occasionally absent in some cases, it is often difficult to differentiate between single canal and multiple canal BPPV involving the anterior semicircular canal by performing the Dix-Hallpike test or the supine straight-head hanging test. In cases of bilateral horizontal canal BPPV, the simultaneous provocation of an excitatory response on one side and an inhibitory response on the other side complicate the diagnosis. Also, various possible combinations of canalolithiasis and cupulolithiasis on either side should be considered in the diagnosis of bilateral horizontal canal BPPV, which makes it more difficult to confirm the diagnosis.

It is generally accepted that multiple canal BPPV is more likely after an event of head trauma, and that both ears are involved after the trauma. ${ }^{4,5,12)}$ Our study population had a relatively low incidence of head trauma, and this may explain the low incidence of bilateral canals involvement among the patients in the present study.

When there is no history of trauma, it can be theoretically thought that it is more likely that otoliths from macula utriculi enter multiple semicircular canals on the same side. From an anatomical point of view, the anterior semicircular canal is less likely to be involved than the other semicircular canals. This is in accordance with the fact that our results, as well as those from previous studies, show that a combination of posterior and horizontal canals is the most frequently involved when multiple canal BPPV affects ipsilaterally., ${ }^{3,6)}$ Our results are in accordance with those from previous studies in which the second most common combination of bilateral involvement, after both posterior canals, is posterior canal on one side and horizontal canal on the other side. ${ }^{3,46)}$ This combination may be related to the fact that in cases of p-BPPV, the patient would tend to turn the head to the unaffected side to relieve vertigo, which may lead to the development of contralateral h-BPPV.

Multiple canal BPPV has been reported to be more likely to be accompanied by an underlying condition, which is also demonstrated in our results $(p<0.05) .{ }^{13)}$ Among the underlying conditions, the incidence of labyrinthitis was significantly higher in the multiple canal BPPV group than in the single canal BPPV group. Theoretically, in the event of labyrinthitis, the inflamed macula utriculi will release more free otoliths, and hence there is a higher chance of these otoliths entering multiple canals. In contrast to other studies, our study failed to demonstrate a definite relationship between multiple canal BPPV and trauma. ${ }^{3,6)}$ This may be related to the relative paucity of patients with head trauma in our hospital or lower rates of inter-departmental consultations, leading to higher chances of missing the diagnosis of BPPV.

The reported effectiveness of treatment for multiple canal $\mathrm{BPPV}$ is quite variable. There is a relatively clear consensus 
about the most effective otolith repositioning procedure for single canal BPPV. ${ }^{14)}$ However, the preferred order of repositioning maneuvers performed for multiple canal BPPV is still unclear. It has been suggested that the canal that causes more intense symptoms and nystagmus should be treated first based on the assumption that this canal harbors more free otoliths than the less-provoking canal. ${ }^{4)}$ Tomaz, et al. ${ }^{6}$ reported that treatment was as effective in multiple canal BPPV as in single canal BPPV, and that there was no difference among the different combinations of affected canals. This was not true in our analysis, as the duration for the disappearance of nystagmus and vertigo symptom lasted longer when multiple canals were involved. More treatment sessions were required for multiple canal BPPV (average 3.2 \pm 2.9 sessions) than for single canal BPPV (average 1.5 \pm 1.1 sessions). Previous studies evaluated the results of treatment at weeks to months after the onset of symptoms and nystagmus, and thus they may have observed a lack of difference in the treatment results between the two BPPV groups. In the present study, we instructed the patients to visit the clinic at an interval of 1-7 days so as to repeat the treatment procedures at short intervals until we observed resolution of vertigo along with nystagmus, and this may explain why we were able to identify a difference in the number of procedures and the duration of treatment between single and multiple canal BPPV. ${ }^{4,7)}$ In the previous study by the authors, it was observed that the number of procedures needed to treat $\mathrm{p}$-BPPV $(1.7 \pm 1.40)$ was significantly lesser than the number of procedures needed to treat h-BPPV $(2.0 \pm 1.25)$, and we can expect that performing the Epley maneuver to treat p-BPPV first would be helpful for achieving quicker recovery when the posterior and horizontal semicircular canals are affected. ${ }^{15)}$

Our results with respect to the clinical characteristics of multiple canal BPPV can be summarized as follows: multiple canal involvement in BPPV is observed in less than 5\% of patients. Patients with multiple canal BPPV need more procedures and longer time to achieve resolution of nystagmus and vertigo symptom as compared to those with single canal BPPV. Multiple canal involvement is more likely in the presence of certain underlying conditions, labyrinthitis in particular. The affected pair of semicircular canals tends to be on the same side with the exception of cases with trauma as an underlying condition.

It may be difficult to make a proper diagnosis of multiple canal BPPV because the 3 semicircular canals are paired with a canal on the opposite side to create a push-pull arrangement in response to head rotation, and interpretation of positional nystagmus for identifying the affected canals can be quite confusing. Despite the fact that cases with multiple canal BPPV required a longer treatment period, all these cases were even- tually treated successfully. Also, previous studies showed that the prognosis or response to otolith repositioning procedures is essentially the same regardless of the number of canals involved in BPPV. Based on these results, we can conclude that multiple canal BPPV can be treated successfully with comparable effectiveness as in single canal BPPV as long as the correct diagnosis is made.

\section{Conclusion}

As all cases of multiple canal BPPV were treated successfully although a longer duration of treatment and more treatment sessions were required compared to single canal BPPV, the results of our study could aid in making an accurate diagnosis and providing appropriate treatment of multiple canal BPPV.

\section{REFERENCES}

1) Kim JS, Zee DS. Clinical practice. Benign paroxysmal positional vertigo. N Engl J Med 2014;370:1138-47.

2) Balatsouras DG, Koukoutsis G, Ganelis P, Korres GS, Kaberos A. Diagnosis of Single- or Multiple-Canal Benign Paroxysmal Positional Vertigo according to the Type of Nystagmus. Int J Otolaryngol 2011; 2011:483965.

3) Balatsouras DG. Benign paroxysmal positional vertigo with multiple canal involvement. Am J Otolaryngol 2012;33:250-8.

4) Soto-Varela A, Rossi-Izquierdo M, Santos-Pérez S. Benign paroxysmal positional vertigo simultaneously affecting several canals: a 46-patient series. Eur Arch Otorhinolaryngol 2013;270:817-22.

5) Pollak L, Stryjer R, Kushnir M, Flechter S. Approach to bilateral benign paroxysmal positioning vertigo. Am J Otolaryngol 2006;27:91-5.

6) Tomaz A, Ganança MM, Ganança CF, Ganança FF, Caovilla HH, Harker L. Benign paroxysmal positional vertigo: concomitant involvement of different semicircular canals. Ann Otol Rhinol Laryngol 2009;118:113-7.

7) Lopez-Escamez JA, Molina MI, Gamiz M, Fernandez-Perez AJ, Gomez M, Palma MJ. Multiple positional nystagmus suggests multiple canal involvement in benign paroxysmal vertigo. Acta Otolaryngol 2005;125:954-61.

8) Bhattacharyya N, Baugh RF, Orvidas L, Barrs D, Bronston LJ, Cass $\mathrm{S}$, et al. Clinical practice guideline: benign paroxysmal positional vertigo. Otolaryngol Head Neck Surg 2008;139(5 Suppl 4):S47-81.

9) Steddin S, Brandt T. Unilateral mimicking bilateral benign paroxysmal positioning vertigo. Arch Otolaryngol Head Neck Surg 1994; 120:1339-41.

10) Kim SH, Jo SW, Chung WK, Byeon HK, Lee WS. A cupulolith repositioning maneuver in the treatment of horizontal canal cupulolithiasis. Auris Nasus Larynx 2012;39:163-8.

11) Yacovino DA, Hain TC, Gualtieri F. New therapeutic maneuver for anterior canal benign paroxysmal positional vertigo. J Neurol 2009; 256:1851-5.

12) Suarez H, Alonso R, Arocena M, Suarez A, Geisinger D. Clinical characteristics of positional vertigo after mild head trauma. Acta Otolaryngol 2011;131:377-81.

13) Del Rio M, Arriaga MA. Benign positional vertigo: prognostic factors. Otolaryngol Head Neck Surg 2004;130:426-9.

14) Lee SH, Kim JS. Benign paroxysmal positional vertigo. J Clin Neurol 2010;6:51-63.

15) Kim JH, Jung EJ, Song CE, Song MH, Park KC, Ko KM, et al. Risk factors for treatment failure in benign paroxysmal positional vertigo. Korean J Otorhinolaryngol-Head Neck Surg 2013;56:74-8. 